\title{
Comparative Study between Endoscopic Ultrasonography and Transabdominal Ultrasonography in the Assessment of Pancreatobiliary Diseases (with Literatures Review)
}

\author{
Taha Ahmed M. Alkarboly, Mohammad Omer Mohammad, Hiwa Abubaker Hussein, \\ Surkew Lateef Mahummod \\ Kurdistan Centre for Gastroenterology \& Hepatology (KCGH), Sulaimani, Iraqi Kurdistan \\ Email: alkarbolytaha@gmail.com,dr_m_omer@yahoo.com,drhiwa77@gmail.com,surkewlateef@gmail.com
}

Received 4 January 2016; accepted 20 February 2016; published 23 February 2016

Copyright (C) 2016 by authors and Scientific Research Publishing Inc.

This work is licensed under the Creative Commons Attribution International License (CC BY).

http://creativecommons.org/licenses/by/4.0/

c) (i) Open Access

\section{Abstract}

Background: Endoscopic ultrasonography (EUS) and transadominal ultrasonography (TUS) are two imaging investigations which can be used to assess pancreatobiliary status, although both of these imaging techniques are operator and machine dependent, but they have different sensitivity and specificity in detecting pancreatobiliary diseases. Objective: To compare the diagnostic value of EUS versus TUS in the assessment of pancreatobiliary diseases. Patients and Methods: This study was conducted in KCGH (Kurdistan Center for Gastroenterology and Hepatology) in Sulaimani city. Iraqi Kurdistan; the duration of study was 14 months and conducted after approval of Iraqi board ethical committee. One hundred cases were enrolled in the study: 52 of them were females and 48 were males; their ages ranged between 16 - 90 years; informed consent was taken from all patients; all patients underwent proper clinical evaluation; TUS, EUS and Oesophagogastroduodenoscopy (OGD), and in some of them (25 patients) Endoscopic Retrograde Cholangiopancreatography (ERCP), CT scan of abdomen and laboratory investigations were done. Results: EUS detected more cases with common bile duct (CBD) dilatation, CBD stones and pancreatic space occupying lesion (SOL) than TUS, but the differences in the results were not statistically significant. Also EUS detected more cases of intra-abdominal lymph nodes (LNs) and ampullary/peri-ampullary neoplasms than TUS and the differences in the results were statistically significant. Conclusions: Eus is more sensitive than TUS in diagnosing CBD dilatation; it has higher sensitivity than TUS in suspected pancreatobiliary neoplasms; furthermore, EUS can be used for staging and resectability assessment of pancreatobiliary neoplasia. 
Keywords

EUS, TUS, ERCP, Pancreatobiliary Diseases, KCGH, Sulaimani, Iraqi Kurdistan

\section{Introduction}

\subsection{Basics of Ultrasound and Rationale for EUS}

Diagnostic ultrasonography is a relatively recently developed technology. Initial reports began to appear in the late 1950s and early 1960s, and ultrasonography rapidly gained acceptance in the 1970s [1].

As with any technology, diagnostic ultrasound has advantages and disadvantages. Advantages include reasonable portability, relatively low cost, and lack of ionizing radiation (as opposed to CT). Disadvantages include that ultrasound is unable to image deep to air-filled structures or extremely dense structures such as bone or calculi. Imaging of the pancreas and distal common bile duct is also greatly limited. In an effort to overcome these limitations, endoscopic ultrasound was developed in the early 1980s [2].

Endoscopic ultrasonography (EUS) incorporates ultrasound technology into the tip of an endoscope to visualize the gastrointestinal wall and surrounding structures. By placing the ultrasound transducer within the body, it is possible to avoid air-filled or bony structures and reduce the distance between the transducer and the region of interest [3]-[8].

EUS has been used to stage tumors of the gastrointestinal tract, pancreas, and bile ducts [9]. Indeed, studies demonstrate that EUS is a highly accurate modality for staging the depth of tumor invasion; unfortunately, there is a difficulty in distinguishing inflammatory versus neoplastic processes via EUS [3].

\subsection{Radial Array versus Linear Array}

Ultrasound imaging is currently available in two primary imaging planes: radial array and curved linear array ("linear"). These imaging planes are determined by the orientation in which the individual piezoelectric crystals are installed on the echoendoscope. Early devices produced by Olympus utilized only radial imaging, whereas early Pentax devices were exclusively linear (although now both companies manufacture both types of devices).

The Olympus transducer has a more distinct curvature and wider field of view compared to the Pentax device, providing imaging of more tissue anterior to the echoendoscope, although these differences do not necessarily imply a distinct advantage of one type over another [5]. Echoendoscopes are now available in both "diagnostic" and "therapeutic" sizes, determined by the diameter of the device channel.

\subsection{Clinical Indications}

\subsubsection{Linear Endoscopic Ultrasound}

\section{1) Pancreatic Cancer}

Linear echoendoscope is widely used in the diagnosis \& primary staging followed by FNA (fine needle aspiration) of either the pancreatic mass itself or of lymph nodes, and to exclude liver metastasis [10]. Both EUS designs appear equivalent for staging pancreatic cancer and assessing vascular invasion but with the added power to perform FNA, the linear array would be the preferred [10]. Using linear echoendoscope Kochman et al. demonstrated that sensitivity and specificity for malignant disease of the pancreas were $80 \%$ and $88.9 \%$, and for benign disease of the pancreas were $93.8 \%$ and $88.2 \%$, respectively.

Very few studies have been conducted comparing the efficacy of the radial versus the curvilinear (linear) array systems [11]; their ability to detect and stage cancer has been similar [12]. EUS is superior to CT in the detection of pancreatic tumors especially with a diameter of less than $25 \mathrm{~mm}$ [13]-[15]. Recently, however, with the advent of MDCT (multidetector CT), this difference has reduced [16] [17]. EUS can also locate lymph node metastasis and vascular infiltration with a higher sensitivity than CT [18]. The potential major drawbacks of EUS include operator dependence, limited visualization of the right hepatic lobe and peritoneal metastasis, additionally, it may be difficult to detect tumor in patients with concomitant chronic pancreatitis, or when the cancer is diffusely infiltrating the whole gland [19] [20]. Despite these limitations, some authors have documented that the negative predictive value (NPV) of EUS for tumor detection is as high as 100\% [21]. 
EUS is particularly helpful in demonstrating the presence of neuroendocrine tumors (NET) with a sensitivity of more than $80 \%$ [22] [23]. It not only localizes the tumor, but also differentiates it from adenocarcinoma [24]. EUS has a higher sensitivity for diagnosing the tumors located in the head of the pancreas than the tumors located at body or tail of the pancreas [25] [26]. A recent review by DeWitt et al., comparing the role of EUS and CT in staging of the pancreatic cancer depicted EUS as superior to CT for T (tumor) staging [13] [27]; and for detecting the invasion of the portal vein; while the invasion of celiac and superior mesenteric arteries were better detected by CT scan [28]. However, the study demonstrated equal efficacy of both EUS and CT scan in N (nodal) staging [29], and determining the tumor respectability [28]. Studies have shown that the sensitivity of cytology (to exclude malignancy) obtained during ERCP to be less than 70\%. Therefore, ERCP should be performed only for biliary decompression [30] [31]. EUS-guided FNA is the preferred procedure due to its ability to detect and stage the lesion, assess resectability, obtain FNA for cytological confirmation, and finally to carry out EUSguided celiac neurolysis in the presence of unresectable tumor with unremitting pain [32] [33]. EUS-FNA of pancreatic masses is of low risk with a reported complication rate of $1 \%-2 \%$ [13]. Most complications are minor and include self-limited bleeding, abdominal pain, and acute pancreatitis. The sensitivity and specificity of EUS-FNA for the diagnosis of pancreatic cancer is $85 \%$ and $98 \%$, respectively [13], and remains extremely accurate even after previously negative tissue sampling from ERCP and percutaneous biopsies. Despite its excellent sensitivity, the negative predictive value of EUS-FNA does not completely exclude the possibility of malignancy; this is particularly true in conditions when pancreatitis accompanies pancreatic cancer [34].

2) Common Bile Duct Stones

EUS has superseded ERCP as the primary endoscopic modality for determining the presence of CBD stones (CBDS); MRCP (magnentic resonance cholangiopancreatography) allows similar accuracy but is limited in stones smaller than $2 \mathrm{~mm}$. Studies in which a radial scanning echoendoscope was used consistently report sensitivities near $90 \%$ for the ability of EUS to detect CBDS. In Lachter et al. study on suspected choledocholithiasis using linear echoendoscope with ERCP serving as the reference [16]. EUS had 97\% sensitivity, 77\% specificity, and 90\% accuracy. The authors conclude that "linear array EUS, despite the learning curve, seems to be about equivalent to radial EUS in accuracy.” Another prospective study of 134 patients suspected of CBDS underwent a linear array examination using (Pentax FG 32 UA, Tokyo, Japan) followed by ERCP with endoscopic sphincterotomy (127 patients), or choledochoscopy [35]. The accuracy for linear array EUS in determining CBDS was 94\%; sensitivity, specificity, positive and negative predictive values were 93\%, 93\%, 98\%, and $87 \%$, respectively.

ERCP is the preferred procedure to treat CBD stones, not to diagnose them due to its attendant morbidity (5\% - 10\%) and imperfect sensitivity (85\% - 90\%) [36] [37]. In a prospective cost-minimization study that enrolled 485 patients with suspected CBD stones investigated by EUS, EUS followed by ERCP in case of positive finding was the least costly strategy (ERCP was avoided in about half patients) [38].

3) "Idiopathic" Acute Pancreatitis

EUS is particularly useful to investigate "idiopathic" acute pancreatitis. Standard investigation of acute pancreatitis, including TUS and CT scan, does not find the cause of acute pancreatitis in 10\% - 20\% of cases [39]. A significant proportion of these cases are unrecognized biliary pancreatitis [39]. This is supported, among other factors by the identification, at microscopic examination, of crystals in bile sampled from the bile duct or gallbladder in up to $80 \%$ of cases [40]. In five studies that have analyzed the results of EUS for acute pancreatitis diagnosed as "idiopathic" after a standard work-up, gallstones were found in 170 (27\%) of 631 patients [41]-[45]. In addition to this, other lesions were detected in another 220 patients, for an overall yield of EUS of 62\% [44]. The likelihood of finding gallstone disease at EUS in idiopathic pancreatitis is similar for a first attack or in case of relapsing disease, but it is low in case of previous cholecystectomy [45]. Recognizing the biliary origin of acute pancreatitis is critical as recurrences develop in 33\% - 61\% of cases in the absence of treatment [46] [47]. To this end, Wilcox et al. recently concluded that EUS should be considered to evaluate patients with a first attack of "idiopathic" acute pancreatitis [48].

4) Biliary Strictures

Eus maliganat characteristics of malignant biliary strictures are: 1) A maximal thickness $\geq 3 \mathrm{~mm} \mathrm{\&} \mathrm{2)} \mathrm{The}$ presence of irregular outer margins [49]. An irregular outer edge of the bile duct wall is also indicative of malignancy, but in contrast; echo features are similar for both benign and malignant strictures (most lesions are hypoechoic compared to the liver) [50]. In a recent meta-analysis, Garrow et al. reviewed 36 studies that analyzed the ability of EUS (without FNA) to detect the presence and etiology of a biliary obstruction in 3532 pa- 
tients. Accuracy of EUS was high for the detection of a biliary obstruction (sensitivity, 88\%; specificity, 90\%), but lower for differentiating benign from malignant causes (sensitivity, 78\%; specificity, 84\%) [51]. Of note, the results of standard EUS (without FNA) were slightly inferior to those reported with magnetic resonance in another meta-analysis, with regard to both the detection of biliary obstruction (sensitivity, 97\%; specificity, 98\%) and the differentiation between benign and malignant biliary obstruction (sensitivity, 88\%; specificity, 95\%) [52]. Regarding lymph nodes, Faigel et al. have shown for pancreatobiliary malignancies; the size of lymph nodes was not associated with malignant involvement, while other commonly used parameters (i.e., a short distance between the tumor and the lymph node, a round shape and a hypoechoic, homogeneous texture of the lymph node) were indicative of malignancy [53]. For cholangiocarcinoma located at the hilum, Gleeson et al. have found that malignant and benign lymph nodes had a similar aspect, including size, roundness, echogenicity, and homogeneity [54]. Cholangiocarcinoma may be more difficult to locate and to sample because they are usually smaller (mean size at the time of FNA, 19 - 24 mm) [49] [50] [55]-[57], and many of them are located in the proximal bile duct, including the hilum. Gleeson et al. reported a retrospective series of 47 patients with unresectable hilar cholangiocarcinoma considered for liver transplantation that had lymph nodes detected at EUS (including 12 with previously undetected lymph nodes by CT and/or magnetic resonance). FNA yielded malignant cells in $17 \%$ of cases [54].

5) Gall Bladder Stones

EUS successfully used for the detection of gallbladder stones that are difficult to detect at TUS due to their small size ( $<3 \mathrm{~mm}$ in diameter), location in the cystic duct, or because of the interposition of adipose tissue in obese patients. A study performed in patients with suspected gallbladder stones and 2 normal TUS examinations, the sensitivity and specificity of EUS for the diagnosis of gallbladder stones were $96 \%$ and $86 \%$, respectively [58]. EUS is most beneficial in patients with "idiopathic” pancreatitis: in a study of 18 patients with negative findings at TUS, 14 (78\%) patients were found to have gallbladder stones at EUS [59].

6) Gall Bladder Carcinoma

Gallbladder carcinoma (GBC) may present as a complex mass filling the gallbladder, or a wall thickening; this latter form represents $18 \%$ of GBC [60]. And is difficult to differentiate from xanthogranulomatous cholecystitis and adenomyomatosis [61]. GBC frequently invades the liver because of the continuity between the perimuscular connective tissue of the gallbladder and the interlobular connective tissue of the liver, and it disseminates to lymph nodes early in the course of the disease (even to nodes posterior to the portal vein or pancreatic head) [62] [63]. Two retrospective studies have analyzed a total of 80 patients with GBC. Lesions were classified into four types, based on tumor characteristics (shape and surface) and integrity of the outer hyperechoic layer of the gallbladder [64] [65]. During EUS, one should also look for previously undetected lymph nodes, liver metastases and carcinomatous ascites because up to $50 \%$ of the patients thought to have a resectable disease have metastasis at staging laparoscopy [66].

Aim of the study:

To compare the diagnostic value of EUS versus TUS in the assessment of pancreatobiliary diseases.

\section{Patients and Methods}

This cross sectional study was conducted over 14 months in KCGH in Sulaiman/Iraqi Kurdistan.

\subsection{Inclusion Criteria}

1) Patients with upper abdominal symptoms like chronic dyspepsia, epigastric or right hypochondrial pain, jaundice; or related symptoms like weight loss for more than two weeks.

2) Patients with a TUS finding or inconclusive findings who needed further assessment by EUS.

3) Patients with pancreatobiliary mass referred for TNM staging or resectability assessment.

\subsection{Exclusion Criteria}

1) Patients with gastric outlet obstruction proved by OGD.

2) Patients aged less than 12 years because of unavailability of pediatric EUS scopes for those ages.

One hundred patients were enrolled in the study. 52 of them were females and 48 were males. Their ages ranged between 16 - 90 years. This study was approved by Iraqi board ethical committee.

Informed consent was taken from all cases; all patients had a proper clinical evaluation. The following inves- 
tigations were done for all patients; TUS, EUS and OGD. And in some of them; ERCP (25 patients), CT scan of abdomen and laboratory investigations were done. Conscious analgesia had been given with $(50 \mathrm{mg})$ pethidine and (2.5 mg) midazolam; with continous monitoring of $\mathrm{O}_{2}$ saturation, pulse rate \& blood pressure during the procedure. The EUS were done by certified gastroenterologists. Two types of EUS devices were used:

1) Olympus GF type UM160 (70 cases);

2) Pentax LH-150PC (30 cases);

The TUS were done by different operators and different devices.

\subsection{Statistical Analysis}

All data were translated into codes and then converted to computerized data base; statistical analysis was done using SPSS 16.0. P value less than 0.05 regarded as statistically significant.

\section{Results}

One hundred cases were enrolled in the study, 52 of them were females and 48 were males, with a female to male ration of 1.1, their age ranges between 16 - 90 years with a mean age of 43 [Figure 1].

Patients' clinical features presentations shown in Figure 2.

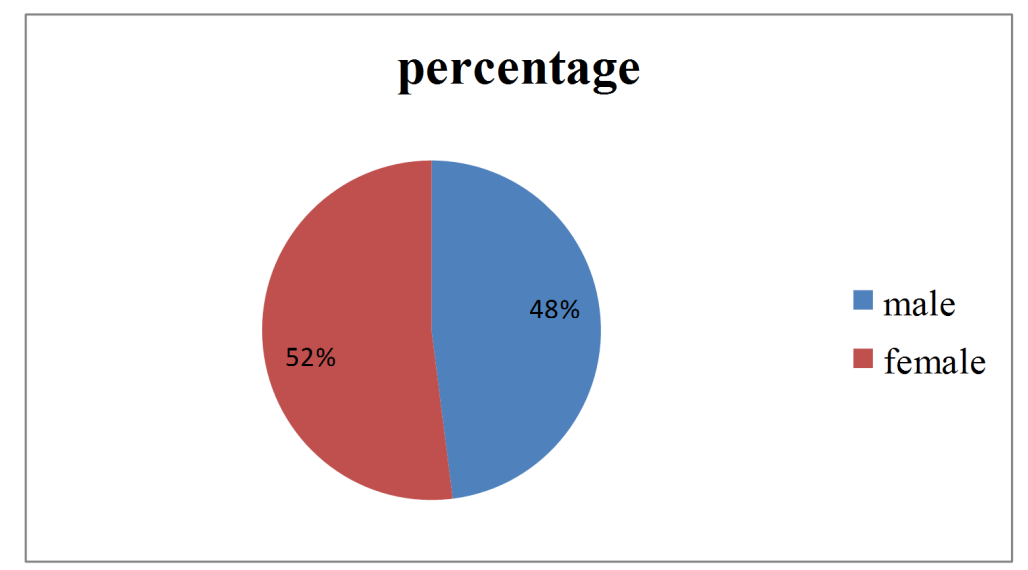

Figure 1. Gender distribution.

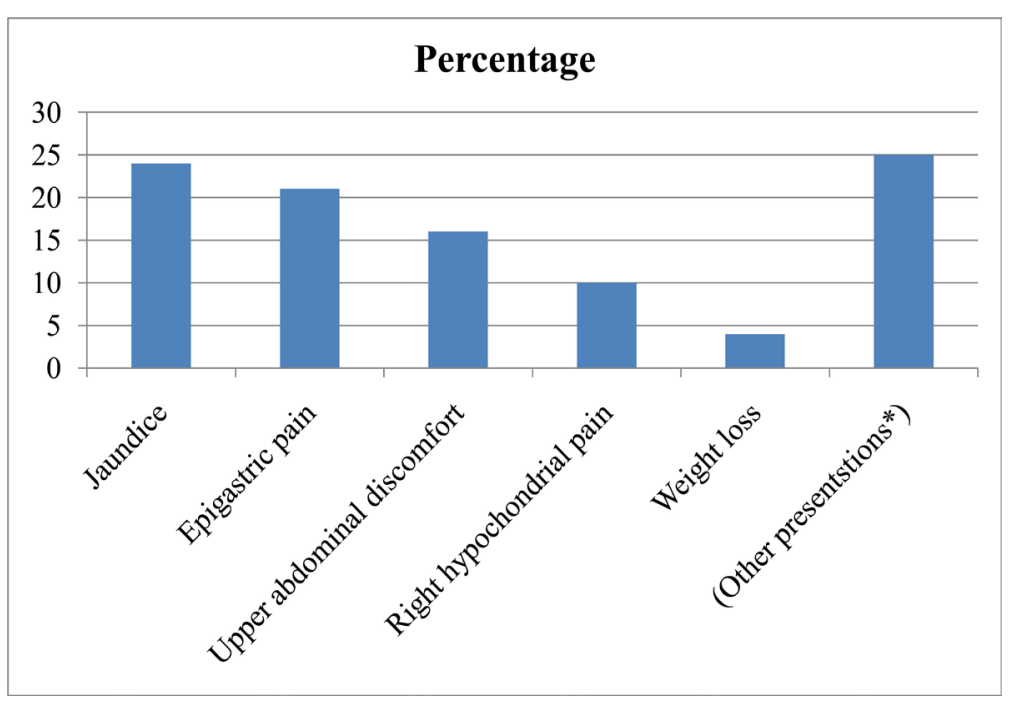

Figure 2. Patients' clinical features presentations. ('Other presentations like; Patients referred for TNM staging or patients have a TUS finding who wanted to be proved by EUS etc.) 
Twelve cases have dilated IHBT (intra hepatic bile tree) by EUS compared to 23 cases by TUS which gives a significant $\mathrm{P}$ value of (0.041), six cases had cystic duct dilatation by TUS compared to nil by EUS which gives a significant $P$ value of (0.013), one case had cystic duct stone by TUS compared to nil by EUS, 45 cases have dilated CBD by EUS compared to 36 cases by TUS, 16 cases have CBD stones by EUS compared to 11 cases by TUS, 8 cases have more than 1 CBD stones by EUS compared to 2 cases by TUS, 6 cases have CBD SOL (space occupying lesions) by both EUS and TUS, 3 cases have CBD sludge by EUS compared to nil by TUS, as shown in Table 1.

Four cases have increased pancreatic size (bulky pancreas) by both EUS and TUS, 2 cases have shrunken pancreas by EUS compared to nil by TUS, 16 cases have pancreatic SOL by EUS compared to 14 cases by TUS, 14 cases have increased MPD (main pancreatic duct) diameter by EUS compared to 11 cases by TUS, 1 case have increased SPD (Small pancreatic duct = 2ndary branches) diameter by both EUS and TUS, As shown in Table 2.

Twelve cases have enlarged LN (lymph node) by EUS compared to only 2 cases by TUS which gives a significant $P$ value of (0.006), among the enlarged LNs. 2 cases have enlarged peripancreatic LNs by EUS compared to nil by TUS, 1 case have enlarged perihepatic LNs by EUS compared to nil by TUS, one case have Para aortic LN enlargement by TUS compared to nil by EUS, 1 case have perigastric LN enlargement by EUS compared to nil by TUS, one case has enlarged periportal LN by EUS compared to nil by TUS, 7 cases have enlarged LNs in places other than mentioned above including (subcarinal, peri-ampullary, periceliac, perilesional) by EUS compared to one case (portahepatis) by TUS, as shown in Table 3.

In addition to the above findings, two cases with pancreatic CA (carcinoma), two cases with cholangiocarcinoma and 5 cases with ampullary/peri-ampullary tumors underwent TNM staging by EUS compared to nil by TUS, as shown in Table 4.

Also in this study; EUS shows other findings include one case of early chronic pancreatitis, one case of pancreatic head fluid collection, one case of pancreatic pseudocysts and three cases of tumor invasion to SMV, CBD and duodenal wall which were not detected by TUS, despite EUS detected nine cases of ampullary/periampullary neoplasms compared to only three cases by TUS, as shown in Table 5.

Table 1. Comparative data analysis of biliary tree by EUS versus TUS.

\begin{tabular}{|c|c|c|c|}
\hline \multirow{2}{*}{ Biliary tree findings } & \multicolumn{2}{|c|}{ Tests } & \multirow{2}{*}{$P$ value } \\
\hline & EUS & TUS & \\
\hline $\begin{array}{c}\text { Intrahepatic biliary tree (IHBT) size } \\
\text { Normal } \\
\text { Increased }\end{array}$ & $\begin{array}{l}88 \\
12\end{array}$ & $\begin{array}{l}77 \\
23\end{array}$ & 0.041 \\
\hline $\begin{array}{l}\text { Cystic duct (CD) size } \\
\text { Normal } \\
\text { Increased }\end{array}$ & $\begin{array}{c}100 \\
0\end{array}$ & $\begin{array}{c}94 \\
6\end{array}$ & 0.013 \\
\hline $\begin{array}{l}\text { CD stone } \\
\text { No } \\
\text { Yes }\end{array}$ & $\begin{array}{c}100 \\
0\end{array}$ & $\begin{array}{c}99 \\
1\end{array}$ & 0.316 \\
\hline $\begin{array}{c}\text { Common bile duct (CBD) size } \\
\text { Normal } \\
\text { Increased }\end{array}$ & $\begin{array}{l}55 \\
45\end{array}$ & $\begin{array}{l}64 \\
36\end{array}$ & 0.195 \\
\hline $\begin{array}{l}\text { CBD stone } \\
\text { No } \\
\text { Yes }\end{array}$ & $\begin{array}{l}84 \\
16\end{array}$ & $\begin{array}{l}89 \\
11\end{array}$ & 0.415 \\
\hline $\begin{array}{l}\text { CBD stone NO. } \\
\text { Single } \\
\text { Multiple }\end{array}$ & $\begin{array}{l}8 \\
8\end{array}$ & $\begin{array}{l}9 \\
3\end{array}$ & 0.126 \\
\hline $\begin{array}{l}\text { CBD SOL } \\
\text { No } \\
\text { Mass } \\
\text { Other }\end{array}$ & $\begin{array}{c}94 \\
4 \\
2\end{array}$ & $\begin{array}{c}94 \\
6 \\
0\end{array}$ & 0.301 \\
\hline $\begin{array}{l}\text { CBD sludge } \\
\text { No } \\
\text { Yes }\end{array}$ & $\begin{array}{c}97 \\
3\end{array}$ & $\begin{array}{c}100 \\
0\end{array}$ & 0.081 \\
\hline
\end{tabular}


Table 2. Comparative data analysis of pancreas by EUS versus TUS.

\begin{tabular}{cccc}
\hline Pancreatic findings & \multicolumn{2}{c}{ Tests } & \multirow{2}{*}{ P value } \\
\cline { 2 - 2 } & EUS & TUS & \\
Pancreatic size & & & \\
Normal & 94 & 96 & 0.364 \\
Increased & 4 & 4 & \\
Shrunken & 2 & 0 & \\
Naccupying lesion & & & \\
No & 84 & 86 & \\
Mass & 7 & 10 & \\
Cyst & 7 & 4 & \\
Other & 2 & 0 & \\
Pancreatic space & & & \\
Normal & 86 & 89 & \\
Increased & 14 & 11 & \\
Main pancreatic duct (MPD) size & & & \\
Normal & 99 & 99 & 0.314 \\
Increased & 1 & 1 & \\
\hline
\end{tabular}

Table 3. Comparative data analysis of lymph nodes by EUS versus TUS.

\begin{tabular}{|c|c|c|c|}
\hline \multirow{2}{*}{ Lymph node findings (LN) } & \multicolumn{2}{|c|}{ Tests } & \multirow{2}{*}{$\mathrm{P}$ value } \\
\hline & EUS & TUS & \\
\hline \multicolumn{4}{|l|}{ LN size } \\
\hline Normal & 87 & 97 & 0.006 \\
\hline Increased & 12 & 2 & \\
\hline \multicolumn{4}{|l|}{ LN enlarged NO. } \\
\hline Single & 10 & 1 & 1.000 \\
\hline Multiple & 2 & 1 & \\
\hline \multicolumn{4}{|l|}{ LN enlarged site } \\
\hline Peripancreatic & 2 & 0 & \\
\hline Perihepatic & 1 & 0 & \\
\hline PARA aortic & 0 & 1 & 0.232 \\
\hline Perigastric & 1 & 0 & \\
\hline Periportal & 1 & 0 & \\
\hline Other sites & 7 & 1 & \\
\hline
\end{tabular}

Table 4. TNM staging of pancreatobiliary carcinoma by EUS.

\begin{tabular}{ccc}
\hline Pancreatobiliary CA detected by EUS & EUS-TNM staging & No. of cases \\
Pancreatic CA & T3, N1, Mx & 1 \\
Pancreatic CA & T3, Nx, Mx & 1 \\
Cholangiocarcinoma & T3, N1, M1 & 1 \\
Cholangiocarcinoma & T2-3, Nx, Mx & 1 \\
Peri-ampullary CA & T4, Mx, Nx & 1 \\
Peri-ampullary CA & T3, N1, Mx & 2 \\
Ampullary CA & T4, Nx, Mx & 1 \\
Ampullary CA & T2-3, Nx, Mx & 1 \\
\hline
\end{tabular}

Among the hundred patients who enrolled in the study; 25 of them underwent ERCP, comparing the result of ERCP and EUS, the sensitivity of EUS for detecting CBD dilatation 56\%, for CBD stones 63\%, for CBD SOL 95\%, and for pancreatic SOL 96\%, as shown in the Table 6.

Also in the study 25 patients underwent ERCP, EUS and TUS. The results of TUS are shown in Table 7. 
Table 5. Other EUS findings compared to TUS and ERCP.

\begin{tabular}{cccc}
\hline Diseases & $\begin{array}{c}\text { Detected by EUS } \\
\text { No. of cases/100 }\end{array}$ & $\begin{array}{c}\text { Detected by TUS } \\
\text { No. of cases/100 }\end{array}$ & $\begin{array}{c}\text { Detected by ERCP } \\
\text { No. of cases/25 }\end{array}$ \\
\hline $\begin{array}{c}\text { Ampullary/peri-ampullary tumors* } \\
\text { Pancreatic head fluid collection }\end{array}$ & 9 & 3 & 3 \\
Strictures & 1 & 0 & 0 \\
Stents (cbd) & 0 & 0 & 4 \\
Tumor invasion of the duodenal wall, CBD and SMV & 10 & 2 & 0 \\
Pancreatic pseudocyst & 3 & 0 & 0 \\
Early chronic pancreatitis & 1 & 0 & 0 \\
\hline
\end{tabular}

${ }^{*} \mathrm{P}$ value 0.041.

Table 6. Sensitivity, specificity, PPV (positive predictive value), and NPD (negative predictive value) of EUS compared to ERCP in 25 patients.

\begin{tabular}{|c|c|c|c|c|}
\hline EUS and ERCP & Sensitivity \% & Specificity \% & PPV \% & NPV \% \\
\hline IHBT size & 76 & 24 & 76 & 24 \\
\hline CBD size & 56 & 88 & 14 & 86 \\
\hline CBD stone & 63 & 36 & 58 & 42 \\
\hline CBD SOL & 95 & 8 & 97 & 3 \\
\hline Pan SOL & 96 & 4 & 95 & 5 \\
\hline MPD size & 88 & 24 & 82 & 18 \\
\hline SPD size & 92 & 0 & 96 & 4 \\
\hline
\end{tabular}

Table 7. Sensitivity, Specificity, PPV, and NPD of TUS compared to ERCP in 25 patients.

\begin{tabular}{|c|c|c|c|c|}
\hline TUS and ERCP & Sensitivity \% & Specificity \% & PPV \% & NPV \% \\
\hline IHBT size & 60 & 35 & 64 & 36 \\
\hline CBD size & 30 & 40 & 36 & 64 \\
\hline CBD stone & 52 & 21 & 72 & 28 \\
\hline MPD size & 50 & 4 & 91 & 9 \\
\hline SPD size & 50 & 4 & 92 & 8 \\
\hline
\end{tabular}

\section{Discussion}

Transabdominal ultrasonography (TUS) is usually used as the initial imaging diagnostic test when choledocholithiasis, cholecystolithiasis and dilatation of biliary tree is suspected [67], because it is non-invasive, widely available, safe, lacks radiation and inexpensive. Despite these benefits its highly operator dependent. However, whole extra hepatic bile ducts are seen in only $60 \%-80 \%$ by TUS [68] [69]. Although EUS is also operator dependent to some extent, its close proximity to the extra hepatic biliary system makes identification and evaluation of biliary tree and GB consistently possible [68]. Female to male ratio was 1.1 probably due to prevalent gall stones diseases in female (Figure 1).

1) CBD dilatation

In the current study $45 \%$ of patients have dilated CBD by EUS compared to $36 \%$ of cases by TUS, although more cases with CBD dilatation were seen by EUS compared to TUS, with a $(P=0.195)$, but the difference in the results was statistically not significant (probably due to small no. in the study), also in this study the sensitivity of EUS for detecting CBD dilatation was 56\% compared to $30 \%$ by TUS.

A study done by Igor Tozzi di Angeloa et al. [70], on one hundred patients in Czech Republic to diagnose CBD dilatation, showed that EUS had sensitivity of $84 \%$ and specificity of $83 \%$, which is significantly higher (P $=0.0001$ ) than TUS which had sensitivity of $46 \%$ and specificity of $66 \%$.

In another study by Stott and colleagues [71], the sensitivity of EUS compared to (ERCP) in detecting com- 
mon bile duct dilatation was 96\%. Which supports the current study result which showed sensitivity of EUS is higher than TUS for detecting CBD dilatation, although the difference was statistically insignificant in this study which could be due to the small number of patients enrolled in the study, experience and operator factors, and another important explanation is that this study was done for pancreatobiliary diseases in general; that's to say not specifically concentrating on CBD dilatation as done in the above studies on CBD diseases.

2) CBD stones

This study showed that sensitivity of EUS for detecting choledocholithiasis was $63 \%$ compared to52\% by TUS, while specificity for EUS in this study was $36 \%$ compared to $21 \%$ by TUS when comparing EUS and TUS by ERCP.

Comparing to a study done by Chak A, et al. [72], which involves thirty six patients, all patients underwent TUS, EUS and ERCP, the sensitivity of EUS for detecting CBD stones was $91 \%$ compared to $50 \%$ by TUS.

Other studies showed sensitivity of EUS for detecting CBD stone ranged from $88 \%$ - 97\% and specificity ranged from $93 \%$ - 100\% [72].

A number of other studies have compared the accuracy of EUS in detection of CBD stones with TUS, ERCP, and CT [73]-[76], in most of these reports, the sensitivity of EUS ranged from $88 \%$ - 97\%, with specificity ranged from $96 \%$ - 100\%. In some other studies the sensitivity of EUS in detecting CBD stones ranges from $92 \%$ - 97\% while that of TUS ranges from 15\% - 56\% in the best hands [77] [78].

The wide range values for TUS can be partially explained by its operator dependency. While in regard to EUS comparing other studies to the current study it supports our result, which showed the sensitivity and specificity of EUS for CBD stones is higher than TUS, although the sensitivity and specificity in the current study is lower than the other studies which could be due to learning curve in this difficult procedure, lack of adequate anaesthesia for irritable patients, old generations of linear scope (fiberopticpentax scope) in the intial part of study among other factors.

3) Pancreatobiliary neoplasms

This study showed the superiority of EUS in patients with inconclusive TUS results for detecting pancreatobiliary neoplasms; it showed that sensitivity of EUS for detecting pancreatic neoplasm is 96\% and for CBD neoplasm 95\%.

A study done by Rosch T, et al. [79], showed that sensitivity of EUS for detecting pancreatic neoplasm were 99\%. In another study by Rasoul Sotoudehmanesh et al. [80], on 107 patients, showed the sensitivity of EUS for detecting neoplastic bile duct obstruction were 100\%. In another study done by DeWitt J et al. [81], 120 patients enrolled, showed sensitivity of EUS for detecting pancreatic neoplasm were $98 \%$.

4) Ampullary/peri-ampullary neoplasms

Current study showed the usefulness of EUS over TUS in the detection of ampullary/peri-ampullaryneoplasms. Among hundred patients enrolled in the study, nine cases were diagnosed to have ampullary/peri-ampullary neoplasms by EUS, compared to only three cases by TUS; with a significant (P value of 0.041).

In a study by Yasuda K et al. [82], on thirteen cases with ampullary carcinoma (CA); the extent of carcinoma was classified in four stages by EUS, the accuracy rate was 83\% for diagnosis and staging of ampullary/periampullary CA.

Significant P value in the current study and high accuracy of EUS in the other study could support our results.

5) Local staging

In this study five cases of ampullary/peri-ampullary tumors and four cases of pancreatic/cholangiocarcinoma underwent TNM staging by EUS compared to nil by TUS $(\mathrm{P}=0.001)$.

Also in the current study, 12 cases out of hundred had LN enlargement by EUS compared to only 2 cases by TUS which gives a significant $\mathrm{P}$ value of (0.006), and three cases had tumor invasion to CBD, pancreatic duct and duodenal wall by EUS compared to nil by TUS.

TUS is usually not recommended for the staging of pancreatic cancer, due to its low accuracy in predicting vascular involvement and tumor respectability [83].

Although a few recent studies recommend TUS for the staging of pancreatic cancer, but most of the authors agree that the sensitivity and specificity of TUS are very low, especially for the visualization of vessel invasion and lymph nodes detection [84].

Globally, the reported accuracies of local staging by EUS in pancreatic cancer ranges from $62 \%$ - 94\%, and those of nodal staging range from $72 \%$ - 92\% [85] [86].

A total of 29 studies were evaluated $(n=1308)$, in which EUS showed a sensitivity for the detection of vas- 
cular invasion of 73\%, with a specificity of $90.2 \%$ [87].

In some other studies the EUS accuracy for N staging ranged from 64\% - 82\% [85].

Over all diagnostic accuracy of EUS for tumor staging in ampullary cancer were 74\% by Artifon [88], and in another study were $63 \%$ by Ito [89].

In the current study despite a significant $\mathrm{P}$ value of (0.006) in detecting LN enlargement by EUS compared to TUS, and nine cases of pancreatobiliary carcinoma underwent TNM staging compared to nil by TUS, but we couldn't calculate sensitivity or accuracy of EUS for local staging, as we haven't access to compare it to the gold standard (for example operative exploration) because of lack of follow up after EUS examination.

\section{Conclusion}

EUS is a relatively new technique in KCGH and needs more training and experience. Eus is more sensitive than TUS in diagnosing CBD dilatation; it has higher sensitivity than TUS in suspected pancreatobiliary neoplasms; furthermore, EUS can be used for staging and resectability assessment of pancreatobiliary neoplasia.

\section{References}

[1] Donald, I., MacVicar, J. and Brown, T.G. (1958) Investigation of Abdominal Masses by Pulsed Ultrasound. Lancet, 1, 1188-1195. http://dx.doi.org/10.1016/S0140-6736(58)91905-6

[2] DiMagno, E.P., Buxton, J.L., Regan, P.T., et al. (1980) Ultrasonic Endoscope. Lancet, 1, 629-631. http://dx.doi.org/10.1016/S0140-6736(80)91122-8

[3] Yanai, H., Yoshida, T., Harada, T., et al. (1996) Endoscopic Ultrasonography of Superficial Esophageal Cancers Using a Thin Ultrasound Probe System Equipped with Switchable. Gastrointestinal Endoscopy, 44, 578-582. http://dx.doi.org/10.1016/S0016-5107(96)70012-3

[4] Hasegawa, N., Niwa, Y., Arisawa, T., et al. (1996) Preoperative Staging of Superficial Esophageal Carcinoma: Comparison of an Ultrasound Probe and Standard Endoscopic Ultrasonography. Gastrointestinal Endoscopy, 44, 388-393. http://dx.doi.org/10.1016/S0016-5107(96)70086-X

[5] Takemoto, T., Yanai, H., Tada, M., et al. (1992) Application of Ultrasonic Probes Prior to Endoscopic Resection of Early Gastric Cancer. Endoscopy, 24, 329-333. http://dx.doi.org/10.1055/s-2007-1010493

[6] May, A., Gunter, E., Roth, F., et al. (2004) Accuracy of Staging in Early Esophageal Cancer Using High Resolution Endoscopy and High Resolution Endosonography: A Comparative, Prospective, and Blinded Trial. Gut, 53, $634-640$. http://dx.doi.org/10.1136/gut.2003.029421

[7] Saitoh, Y., Obara, T., Einami, K., et al. (1996) Efficacy of High-Frequency Ultrasound Probes for the Preoperative Staging of Invasion Depth in Flat and Depressed Colorectal Tumors. Gastrointestinal Endoscopy, 44, 34-39. http://dx.doi.org/10.1016/S0016-5107(96)70226-2

[8] Yoshida, M., Tsukamoto, Y., Niwa, Y., et al. (1995) Endoscopic Assessment of Invasion of Colorectal Tumors with a New High Frequency Ultrasound Probe. Gastrointestinal Endoscopy, 41, 587-592. http://dx.doi.org/10.1016/S0016-5107(95)70196-6

[9] Gan, S.I., Rajan, E., Adler, D.G., et al. (2007) Role of EUS. Gastrointestinal Endoscopy, 66, 425-434. http://dx.doi.org/10.1016/j.gie.2007.05.026

[10] Kochman, M.L., Elta, G.H., Bude, R., et al. (1998) Utility of a Linear Array Ultrasound Endoscope in the Evaluation of Suspected Pancreatic Disease. Journal of Gastrointestinal Surgery, 2, 217-222. http://dx.doi.org/10.1016/S1091-255X(98)80015-2

[11] Gress, F., Savides, T., Cummings, O., et al. (1997) Radial Scanning and Linear Array Endosonography for Staging Pancreatic Cancer: A Prospective Randomized Comparison. Gastrointestinal Endoscopy, 45, 138-142. http://dx.doi.org/10.1016/S0016-5107(97)70236-0

[12] Kochman, M.L., Elta, G.H., Bude, R., et al. (1998) Utility of a Linear Array Ultrasound Endoscope in the Evaluation of Suspected Pancreatic Disease. Journal of Gastrointestinal Surgery, 2, 217-222. http://dx.doi.org/10.1016/S1091-255X(98)80015-2

[13] De Witt, J. (2006) EUS and Pancreatic Tumors. In: Hawes, R. and Fockens, P., Eds., Endosonography, Elsevier Press, London.

[14] Rosch, T., Lorenz, R., Braig, C., et al. (1991) Endoscopic Ultrasound in Pancreatic Tumor Diagnosis. Gastrointestinal Endoscopy, 37, 347-352. http://dx.doi.org/10.1016/s0016-5107(91)70729-3

[15] Legmann, P., Vignaux, O., Dousset, B., et al. (1998) Pancreatic Tumors: Comparison of Dual-Phase Helical CT and Endoscopic Sonography. American Journal of Roentgenology, 170, 1315-1322. 
http://dx.doi.org/10.2214/ajr.170.5.9574609

[16] Lachter, J., Rubin, A., Shiller, M., et al. (2000) Linear EUS for Bile Duct Stones. Gastrointestinal Endoscopy, 51, 5154. http://dx.doi.org/10.1016/s0016-5107(00)70387-7

[17] Del Frate, C., Zanardi, R., Mortele, K., et al. (2002) Advances in Imaging for Pancreatic Disease. Current Gastroenterology Reports, 4, 140-148. http://dx.doi.org/10.1007/s11894-002-0051-X

[18] Rosewicz, S. and Wiedenmann, B. (1997) Pancreatic Carcinoma. The Lancet, 349, 485-489. http://dx.doi.org/10.1016/S0140-6736(96)05523-7

[19] Muller, M.F., Meyenberger, C., Bertschinger, P., et al. (1994) Pancreatic Tumors: Evaluation with Endoscopic US, CT, and MR Imaging. Radiology, 190, 745-751. http://dx.doi.org/10.1148/radiology.190.3.8115622

[20] Bhutani, M.S., Gress, F.G., Giovannini, M., et al. (2004) The No Endosonography Detection of Tumor (NEST) Study: A Case Series of Pancreatic Cancers Missed on Endoscopic Ultrasonography. Endoscopy, 36, 385-389. http://dx.doi.org/10.1055/s-2004-814320

[21] Klapman, J.B., Chang, K.J., Lee, J.G., et al. (2005) Negative Predictive Value of Endoscopic Ultrasound in a Large Series of Patients with a Clinical Suspicion of Pancreatic Cancer. American Journal of Gastroenterology, 100, 26582661. http://dx.doi.org/10.1111/j.1572-0241.2005.00315.x

[22] Chatzipantelis, P., Salla, C., Konstantinou, P., et al. (2008) Endoscopic Ultrasound-Guided Fine-Needle Aspiration Cytology of Pancreatic Neuroendocrine Tumors: A Study of 48 Cases. Cancer, 114, 255-262. http://dx.doi.org/10.1002/cncr.23637

[23] Ardengh, J.C., de Paulo, G.A. and Ferrari, A.P. (2004) EUS-Guided FNA in the Diagnosis of Pancreatic Neuroendocrine Tumors before Surgery. Gastrointestinal Endoscopy, 60, 378-384. http://dx.doi.org/10.1016/S0016-5107(04)01807-3

[24] McLean, A.M. and Fairclough, P.D. (2005) Endoscopic Ultrasound in the Localization of Pancreatic Islet Cell Tumors. Best Practice \& Research Clinical Endocrinology \& Metabolism, 19, 177-193. http://dx.doi.org/10.1016/j.beem.2004.11.012

[25] Rosch, T., Lightdale, C.J., Botet, J.F., et al. (1992) Localization of Pancreatic Endocrine Tumors by Endoscopic Ultrasonography. The New England Journal of Medicine, 326, 1721-1726. http://dx.doi.org/10.1056/NEJM199206253262601

[26] Soria, M.T., Gines, A., Belda, J., et al. (2002) Usefulness of Endoscopic Ultrasound-Guided Fine Needle Aspiration (EUS-G FNA) in Diagnosing the Extension of Non-Small Cell Lung Cancer. Archivos de Bronconeumología, 38, 536541.

[27] DeWitt, J., Devereaux, B.M., Lehman, G.A., et al. (2006) Comparison of Endoscopic Ultrasound and Computed Tomography for the Preoperative Evaluation of Pancreatic Cancer: A Systematic Review. Clinical Gastroenterology and Hepatology, 4, 717-725.

[28] Bottger, T.C. and Junginger, T. (1993) Is Preoperative Radiographic Localization of Islet Cell Tumors in Patients with Insulinoma Necessary. World Journal of Surgery, 17, 427-432. http://dx.doi.org/10.1007/BF01655099

[29] Valls, C., Andia, E., Sanchez, A., et al. (2002) Dual Phase Helical CT of Pancreatic Adenocarcinoma: Assessment of Resectability before Surgery. American Journal of Roentgenology, 178, 821-826. http://dx.doi.org/10.2214/ajr.178.4.1780821

[30] Ponchon, T., Gagnon, P., Berger, F., et al. (1995) Value of Endobiliary Brush Cytology and Biopsies for the Diagnosis of Malignant Bile Duct Stenosis: Results of a Prospective Study. Gastrointestinal Endoscopy, 42, 565-572. http://dx.doi.org/10.1016/s0016-5107(95)70012-9

[31] Pugliese, V., Conio, M., Nicolo, G., et al. (1995) Endoscopic Retrograde Forceps Biopsy and Brush Cytology of Biliary Strictures: A Prospective Study. Gastrointestinal Endoscopy, 42, 520-526. http://dx.doi.org/10.1016/s0016-5107(95)70004-8

[32] Santo, E. (2004) Pancreatic Cancer Imaging: Which Method? Journal of the Pancreas, 5, 253-257.

[33] Horwhat, J.D., Paulson, E.K., McGrath, K., et al. (2006) A Randomized Comparison of EUS-Guided FNA versus CT or US-Guided FNA for the Evaluation of Pancreatic Mass Lesions. Gastrointestinal Endoscopy, 63, 966-975. http://dx.doi.org/10.1016/j.gie.2005.09.028

[34] Gress, F., Gottlieb, K., Sherman, S., et al. (2001) Endoscopic Ultrasonography-Guided Fine-Needle Aspiration Biopsy of Suspected Pancreatic Cancer. Annals of Internal Medicine, 134, 459-464. http://dx.doi.org/10.7326/0003-4819-134-6-200103200-00010

[35] Kohut, M., Dulawa, E.N., Marek, T., et al. (2002) Accuracy of Endoscopic Ultrasonography in the Evaluation of Patients with Suspected Common Bile Duct Stones. Endoscopy, 34, 299-303. http://dx.doi.org/10.1055/s-2002-23641

[36] Koito, K., Namieno, T., Nagakawa, T., et al. (1997) Solitary Cystic Tumor of the Pancreas: EUS-Pathologic Correla- 
tion. Gastrointestinal Endoscopy, 45, 268-276. http://dx.doi.org/10.1016/S0016-5107(97)70269-4

[37] Gress, F., Gottlieb, K., Cummings, O., et al. (2009) Endoscopic Ultrasound Characteristics of Mucinous Cystic Neoplasms of the Pancreas. The American Journal of Gastroenterology, 95, 961-965. http://dx.doi.org/10.1111/j.1572-0241.2000.01976.x

[38] Ahmad, N.A., Kochman, M.L., Lewis, J.D., et al. (2001) Can EUS Alone Differentiate between Malignant and Benign Cystic Lesions of the Pancreas. The American Journal of Gastroenterology, 96, 3295-3300. http://dx.doi.org/10.1111/j.1572-0241.2001.05328.x

[39] Wilcox, C.M., Varadarajulu, S. and Eloubeidi, M. (2006) Role of Endoscopic Evaluation in Idiopathic Pancreatitis: A Systematic Review. Gastrointestinal Endoscopy, 63, 1037-1045. http://dx.doi.org/10.1016/j.gie.2006.02.024

[40] Kohut, M., Nowak, A., Nowakowska-Duława, E., et al. (2001) The Frequency of Bile Duct Crystals in Patients with Presumed Biliary Pancreatitis. Gastrointestinal Endoscopy, 54, 37-41. http://dx.doi.org/10.1067/mge.2001.115475

[41] Frossard, J.L., Sosa-Valencia, L., Amouyal, G., et al. (2000) Usefulness of Endoscopic Ultrasonography in Patients with "Idiopathic” Acute Pancreatitis. American Journal of Medicine, 109, 196-200. http://dx.doi.org/10.1016/S0002-9343(00)00478-2

[42] Liu, C.L., Lo, C.M., Chan, J.K., et al. (2000) EUS for Detection of Occult Cholelithiasis in Patients with Idiopathic Pancreatitis. Gastrointestinal Endoscopy, 51, 28-32. http://dx.doi.org/10.1016/s0016-5107(00)70382-8

[43] Norton, S.A. and Alderson, D. (2000) Endoscopic Ultrasonography in the Evaluation of Idiopathic Acute Pancreatitis. British Journal of Surgery, 87, 1650-1655. http://dx.doi.org/10.1046/j.1365-2168.2000.01587.x

[44] Tandon, M. and Topazian, M. (2001) Endoscopic Ultrasound in Idiopathic Acute Pancreatitis. The American Journal of Gastroenterology, 96, 705-709. http://dx.doi.org/10.1111/j.1572-0241.2001.03609.X

[45] Yusoff, I.F., Raymond, G. and Sahai, A.V. (2004) A Prospective Comparison of the Yield of EUS in Primary vs. Recurrent Idiopathic Acute Pancreatitis. Gastrointestinal Endoscopy, 60, 673-678. http://dx.doi.org/10.1016/S0016-5107(04)02018-8

[46] Frei, G.J., Frei, V.T., Thirlby, R.C., et al. (1986) Biliary Pancreatitis: Clinical Presentation and Surgical Management. American Journal of Surgery, 151, 170-175. http://dx.doi.org/10.1016/0002-9610(86)90028-0

[47] Goodman, A.J., Neoptolemos, J.P., Carr-Locke, D.L., et al. (1985) Detection of Gall Stones after Acute Pancreatitis. Gut, 26, 125-132. http://dx.doi.org/10.1136/gut.26.2.125

[48] Aldouri, A., Malik, H., Waytt, J., et al. (2009) The Risk of Gallbladder Cancer from Polyps in a Large Multiethnic Series. European Journal of Surgical Oncology, 35, 48-51.

[49] Lee, J.H., Salem, R., Aslanian, H., et al. (2004) Endoscopic Ultrasound and Fine-Needle Aspiration of Unexplained Bile Duct Strictures. The American Journal of Gastroenterology, 99, 1069-1073. http://dx.doi.org/10.1111/j.1572-0241.2004.30223.x

[50] Fritscher-Ravens, A., Broering, D.C., Knoefel, W.T., et al. (2004) EUS-Guided Fine-Needle Aspiration of Suspected Hilar Cholangiocarcinoma in Potentially Operable Patients with Negative Brush Cytology. The American Journal of Gastroenterology, 99, 45-51. http://dx.doi.org/10.1046/j.1572-0241.2003.04006.x

[51] Garrow, D., Miller, S., Sinha, D., et al. (2007) Endoscopic Ultrasound: A Meta-Analysis of Test Performance in Suspected Biliary Obstruction. Clinical Gastroenterology and Hepatology, 5, 616-623. http://dx.doi.org/10.1016/j.cgh.2007.02.027

[52] Romagnuolo, J., Bardou, M., Rahme, E., et al. (2003) Magnetic Resonance Cholangiopancreatography: A MetaAnalysis of Test Performance in Suspected Biliary Disease. Annals of Internal Medicine, 139, 547-557. http://dx.doi.org/10.7326/0003-4819-139-7-200310070-00006

[53] Faigel, D.O. (2001) EUS in Patients with Benign and Malignant Lymphadenopathy. Gastrointestinal Endoscopy, 53, 593-598. http://dx.doi.org/10.1067/mge.2001.114060

[54] Gleeson, F., Rajan, E., Levy, M., et al. (2008) EUS Guided FNA of Regional Lymph Nodes in Patients with Unresectable Hilar Cholangiocarcinoma. Gastrointestinal Endoscopy, 67, 438-443. http://dx.doi.org/10.1016/j.gie.2007.07.018

[55] DeWitt, J., Misra, V.L., Leblanc, J.K., et al. (2006) EUS-Guided FNA of Proximal Biliary Strictures after Negative ERCP Brush Cytology Results. Gastrointestinal Endoscopy, 64, 325-333. http://dx.doi.org/10.1016/j.gie.2005.11.064

[56] Eloubeidi, M.A., Chen, V.K., Jhala, N.C., et al. (2004) Endoscopic Ultrasound-Guided Fine Needle Aspiration Biopsy of Suspected Cholangiocarcinoma. Clinical Gastroenterology and Hepatology, 2, 209-213. http://dx.doi.org/10.1016/s1542-3565(04)00005-9

[57] Meara, R.S., Jhala, D., Eloubeidi, M.A., et al. (2006) Endoscopic Ultrasound-Guided FNA Biopsy of Bile Duct and Gallbladder: Analysis of 53 Cases. Cytopathology, 17, 42-49. http://dx.doi.org/10.1111/j.1365-2303.2006.00319.x

[58] Dahan, P., Andant, C., Levy, P., et al. (1996) Prospective Evaluation of Endoscopic Ultrasonography and Microscopic Examination of Duodenal Bile in the Diagnosis of Cholecystolithiasis in 45 Patients with Normal Conventional Ultra- 
sonography. Gut, 38, 277-281. http://dx.doi.org/10.1136/gut.38.2.277

[59] Liu, C.L., Lo, C.M., Chan, J.K., et al. (2000) EUS for Detection of Occult Cholelithiasis in Patients with Idiopathic Pancreatitis. Gastrointestinal Endoscopy, 51, 28-32. http://dx.doi.org/10.1016/s0016-5107(00)70382-8

[60] Chijiiwa, K., Sumiyoshi, K. and Nakayama, F. (1991) Impact of Recent Advances in Hepatobiliary Imaging Techniques on the Preoperative Diagnosis of Carcinoma of the Gallbladder. World Journal of Surgery, 15, 322-327. http://dx.doi.org/10.1007/BF01658723

[61] Boujaoude, J. (2007) Role of Endoscopic Ultrasound in Diagnosis and Therapy of Pancreatic Adenocarcinoma. World Journal of Gastroenterology, 13, 3662-3666.

[62] Levy, A.D., Murakata, L.A. and Rohrmann, C.A. (2001) Gallbladder Carcinoma: Radiologic-Pathologic Correlation. Radiographics, 21, 295-314. Questionnaire, 549-555.

[63] Shirai, Y., Yoshida, K., Tsukada, K., et al. (1992) Identification of the Regional Lymphatic System of the Gallbladder by Vital Staining. British Journal of Surgery, 79, 659-662. http://dx.doi.org/10.1002/bjs.1800790721

[64] Fujita, N., Noda, Y., Kobayashi, G., et al. (1999) Diagnosis of the Depth of Invasion of Gallbladder Carcinoma by EUS. Gastrointestinal Endoscopy, 50, 659-663. http://dx.doi.org/10.1016/S0016-5107(99)80015-7

[65] Sadamoto, Y., Kubo, H., Harada, N., et al. (2003) Preoperative Diagnosis and Staging of Gallbladder Carcinoma by EUS. Gastrointestinal Endoscopy, 58, 536-541. http://dx.doi.org/10.1067/S0016-5107(03)01961-8

[66] Weber, S.M., DeMatteo, R.P., Fong, Y., et al. (2002) Staging Laparoscopy in Patients with Extrahepatic Biliary Carcinoma. Analysis of 100 Patients. Annals of Surgery, 235, 392-399.

http://dx.doi.org/10.1097/00000658-200203000-00011

[67] Kohut, M., Nowakowska-Dulawa, E., Marek, T., et al. (2002) Accuracy of Linear Endoscopic Ultrasonography in the Evaluation of Patients with Suspected Common Bile Duct Stones. Endoscopy, 34, 299-303. http://dx.doi.org/10.1055/s-2002-23641

[68] Sugiyama, M. and Atomi, Y. (1997) Endoscopic Ultrasonography for Diagnosing Choledocholithiasis: A Prospective Comparative Study with Ultrasonography and Computed Tomography. Gastrointestinal Endoscopy, 45, 143-146. http://dx.doi.org/10.1016/s0016-5107(97)70237-2

[69] Di Nardo, R., Urbano, D., Drudi, F.M., et al. (1996) Ultrasonography in the Preoperative Assessment of Candidates for Laparospic Cholecystectomy: Examination Technique and Results. Radiologia Medica, 92, 605-609.

[70] Tozzi Di, I.A., Prochazka, V., Holinka, M., et al. (2011) Endosonography versus Endoscopic Retrograde Cholangiopancreatography in Diagnosing Extrahepatic Biliary Obstruction. Biomedical Papers, 155, 339-346. http://dx.doi.org/10.5507/bp.2011.044

[71] Stott, M.A., Farrands, P.A., Guyer, P.B., et al. (1991) Ultrasound of the Common Bile Duct in Patients Undergoing Cholecystectomy. Journal of Clinical Ultrasound, 19, 73-76. http://dx.doi.org/10.1002/jcu.1870190203

[72] Napoleon, B., Dumortier, J., Keriven-Souquet, O., et al. (2003) Do Normal Findings at Biliary Endoscopic Sonography Obviate the Need for Endoscopic Retrograde Cholangiography in Patients with Suspicion of Common Bile Duct Stone a Prospective Follow-Up Study of 238 Patients. Endoscopy, 35, 411-415. http://dx.doi.org/10.1055/s-2003-38778

[73] Kohut, M., Nowakowska-Dulawa, E., Marek, T., et al. (2002) Accuracy of Linear Endoscopic Ultrasonography in the Evaluation of Patients with Suspected Common Bile Duct Stones. Endoscopy, 34, 299-303. http://dx.doi.org/10.1055/s-2002-23641

[74] Buscarini, E., Tansini, P., Vallisa, D., et al. (2003) EUS for Suspected Choledocholithiasis: Do Benefits Outweigh Costs a Prospective, Controlled Study. Gastrointestinal Endoscopy, 57, 510-518. http://dx.doi.org/10.1067/mge.2003.149

[75] Amouyal, P., Amouyal, G., Levy, P., et al. (1994) Diagnosis of Choledocholithiasis by Endoscopic Ultrasonography. Gastroenterology, 106, 1062-1067.

[76] Sugiyama, M. and Atomi, Y. (1997) Endoscopic Ultrasonography for Diagnosing Anomalous Pancreaticobiliary Junction. Gastrointestinal Endoscopy, 45, 261-267. http://dx.doi.org/10.1016/S0016-5107(97)70268-2

[77] Dancygier, H. and Nattermann, C. (1994) The Role of Endoscopic Ultrasonography in Biliary Tract Disease: Obstructive Jaundice. Endoscopy, 26, 800-802. http://dx.doi.org/10.1055/s-2007-1009111

[78] Songur, Y., Temucin, G. and Sahin, B. (2001) Endoscopic Ultrasonography in the Evaluation of Dilated Common Bile Duct. Journal of Clinical Gastroenterology, 33, 302-305. http://dx.doi.org/10.1097/00004836-200110000-00009

[79] Rosch, T., Lorenz, R., Braig, C., et al. (1991) Endoscopic Ultrasound in Pancreatic Tumor Diagnosis. Gastrointestinal Endoscopy, 37, 347-352. http://dx.doi.org/10.1016/S0016-5107(91)70729-3

[80] Sotoudehmanesh, R., Khatibian, M., Ghadir, M.-R., et al. (2011) Diagnostic Accuracy of Endoscopic Ultrasonography in Patients with Inconclusive Magnetic Resonance Imaging Diagnosis of Biliopancreatic Abnormalities. Indian Journal of Gastroenterology, 30, 156-160. 
[81] DeWitt, J., Devereaux, B., Chriswell, M., et al. (2004) Comparison of Endoscopic Ultrasound and Multidetector Computed Tomography for the Detection and Staging of Pancreatic Cancer. Annals of Internal Medicine, 141, 753-763. http://dx.doi.org/10.7326/0003-4819-141-10-200411160-00006

[82] Yasuda, K., Mukai, H., Cho, E., et al. (1988) The Use of Endoscopic Ultrasonography in the Diagnosis and Staging of Carcinoma of the Papilla of Vater. Endoscopy, 20, 218-222.

[83] Di Magno, E.P., Reber, H.A. and Tempero, M.A. (1999) American Gastroenterological Association Technical Review on the Epidemiology, Diagnosis, and Treatment of Pancreatic Ductal Adenocarcinoma. Gastroenterology, 117, 14641484. http://dx.doi.org/10.1016/S0016-5085(99)70298-2

[84] Gandolfi, L., Torresan, F., Solmi, F., et al. (2003) The Role of Ultrasound in Biliary and Pancreatic Diseases. European Journal of Ultrasound, 16, 141-159. http://dx.doi.org/10.1016/S0929-8266(02)00068-X

[85] Tio, T.L., Tytgat, G.N., Cikot, R.J., et al. (1990) Ampullopancreatic Carcinoma: Preoperative TNM Classification with Endosonography. Radiology, 175, 455-461. http://dx.doi.org/10.1148/radiology.175.2.2183284

[86] Seicean, A., Badea, R., Mocan, T., et al. (2008) Radial Endoscopic Ultrasonography in the Preoperative Staging of Pancreatic Cancer. Journal of Gastrointestinal and Liver Diseases, 17, 273-278.

[87] Puli, S.R., Singh, S., Hagedorn, C.H., et al. (2007) Diagnostic Accuracy of EUS for Vascular Invasion in Pancreatic and Periampullary Cancers: A Meta-Analysis and Systematic Review. Gastrointestinal Endoscopy, 65, 788-797. http://dx.doi.org/10.1016/j.gie.2006.08.028

[88] Artifon, E.L.A., Couto Jr., D., Sakai, P., et al. (2009) Prospective Evaluation of EUS versus CT Scan for Staging of Ampullary Cancer. Gastrointestinal Endoscopy, 70, 290-296. http://dx.doi.org/10.1016/j.gie.2008.11.045

[89] Ito, K., Fujita, N., Noda, Y., et al. (2007) Preoperative Evaluation of Ampullary Neoplasm with EUS and Transpapillary Intraductal US: A Prospective and Histopathologically Controlled Study. Gastrointestinal Endoscopy, 60, 740-747. http://dx.doi.org/10.1016/j.gie.2007.03.1081 